\title{
EVALUACIÓN DE LA CONVENIENCIA DE LOS MACROTÚNELES EN COMPARACIÓN CON MICROTÚNELES PARA EL CULTIVO DE FRUTILLA EN CORONDA
}

\author{
Pernuzzi, C. ${ }^{1}$; Sordo, M. $\mathrm{H}^{2}{ }^{2}$ Travadelo, M. ${ }^{1}$; Maina, M. ${ }^{1}$ \& Acetta, P. ${ }^{1}$
}

\begin{abstract}
RESUMEN
El uso del macrotúnel forma parte de las últimas tecnologías incorporadas al cultivo de frutilla en la zona de Coronda (Santa Fe) con un alto nivel de aceptación. El objetivo del presente trabajo fue realizar la evaluación de un proyecto de inversión de una hectárea de macrotúneles dedicada al cultivo de frutillas, comparada con la estructura hasta ahora más usada de microtúneles. A partir de la metodología propia de la formulación y evaluación de proyectos a una tasa de corte de $15 \%$ y a 10 años, se elaboró el flujo de caja siguiendo un criterio incremental, microtúneles vs macrotúneles. El VAN obtenido fue de 1.986 .581 \& una TIR de $107,5 \%$, criterios aceptables para confirmar la conveniencia de la inversión. Al menos la producción del macrotúnel debería ser de 2.369 kg adicionales respecto al microtúnel para que se justifique la inversión, siendo el período de repago de2 años.

Palabras clave: frutilla, macrotúneles, proyecto de inversión, plasticultura, estructuras protegidas.
\end{abstract}

\footnotetext{
ABSTRACT

High tunnelsare the main technological incorporation in strawberry cultivation in the last years in the area of Coronda (Santa Fe).

The objective of the present work was to evaluate an investment project of one hectare of high tunnels compared to the traditional structure of micro tunnels. Based on the methodology of the formulation and evaluation of projects at a breakeven point of $15 \%$ and 10 years, the cash flow was elaborated following an incremental criterion, high tunnels vs. micro tunnels. The obtained NPV

* Elaborado en el marco del Proyecto CAID UNL 2011 - "Viabilidad de diferentes alternativas de valorización y diferenciación de la producción frutícola de la región Central de Santa Fe".

1.- Facultad de Ciencias Agrarias (UNL). 86-Kreder 2805, S3080HOF Esperanza, provincia de Santa Fe.

Email cpernuzzi@fca.unl.edu.ar

2.- AER INTA Monte Vera - OIT Coronda - Rivadavia $17561^{\circ} \mathrm{Piso}$. Coronda (Santa Fe).

Email: sordo.maria@inta.gob.ar

Manuscrito recibido el 18 de octubre de 2016 y aceptado para su publicación el 8 de marzo de 2017.
} 


\section{Pernuzzi et al.}

was $\$ 1,986,581$ and an IRR of $107.5 \%$, acceptable criteria to confirm the appropriateness of the investment. At least the additional production of the high tunnel should be an additional $2.369 \mathrm{~kg}$ with respect to the micro tunnels to justify the investment, with the repayment period of 2 years.

Key words: strawberry, high tunnels, investment project, plasticulture, protected structures.

\section{INTRODUCCIÓN}

En los últimos años los cambios tecnológicos acontecidos han sido trascendentales en el sostenimiento de la rentabilidad del sector frutillero de Coronda (Departamento San Jerónimo, provincia de Santa Fe). Estos cambios tecnológicos han permitido a las empresas, alargar el período de cosecha, mejorar la calidad, aumentar la productividad e incluso realizar inversiones dentro del sector, condición necesaria para mantener y sostener este proceso de cambio en el tiempo.

El uso del macrotúnel en el cultivo de frutilla no es un evento aislado y forma parte de las últimas tecnologías incorporadas al cultivo. Su alto nivel de aceptación entre los productores de Coronda, demuestra que esta tecnología está incorporada y es un factor clave en el proceso productivo. Conocer las variables por el cual esta tecnología fue incorporada es fundamental para comprender este proceso.

En la necesidad de avanzar en la investigación acerca de la utilización de macrotúneles para caracterizar los efectos en la producción de frutilla para cada zona agroecológica (6), en el año 2008 comenzaron en Coronda los primeros ensayos con el objetivo de aumentar el volumen de primicia entre los meses de mayo a agosto, con resultados muy satisfactorios (17).
Las principales ventajas asociadas al uso de este tipo de estructura, entre otras, se pueden clasificar en Ventajas de Estructura, de Protección, de Manejo, y Productivas (Tabla 1).

El objetivo de este trabajo fue realizar la evaluación de un proyecto de inversión de una hectárea de macrotúneles, comparada con la estructura tradicional de microtúneles, siendo estos tipos de estructuras habituales en la producción de frutilla en la zona de Coronda.

\section{METODOLOGÍA}

\section{La estructura tradicional: los microtúneles}

Los Microtúneles son estructuras sencillas que cubren un único surco de cultivo y están construidos con barras de hierro liso de $6 \mathrm{~mm}$ de diámetro (arcos), polietileno de Larga Duración (LD) o Larga Duración Térmica (LDT) de 80 a 100 micrones de espesor (cobertura) y un sistema de sujeción con hilo (atado) (9) (Tabla 1), cuyos principales parámetros son:

Diámetro del hierro: $6 \mathrm{~mm}$

Longitud del arco extendido: 2,2 a $2,4 \mathrm{~m}$

Altura del arco colocado: 60 a $75 \mathrm{~cm}$

Distancia entre Arcos: 3,5 a $4 \mathrm{~m}$

Cantidad de Arcos/ha: 2.100 a 2.350 ar$\cos$.

Revista FAVE - Ciencias Agrarias 15 (2) 2016 